\title{
La resurrección de la Hija de Jairo (Mc 5,21-24a. 35-43 par.) ANÁLISIS HISTÓRICO-TRADICIONAL *
}

\author{
“TALITHÁ, QÛM: ¡JOVENCITA, LEVÁNTATE!
}

En el contexto de los Evangelios ocupan un destacado puesto los milagros de Jesús. Más apropiadamente aquéllos son signos de su dignidad mesiánica y del por él inaugurado reino de Dios: significan su señorío y el de su mesiánico Enviado sobre el esclavizante sufrimiento y la tiranizadora muerte. Signos del inaugurado dominio divino y mesiánico sobre aquélla, por Jesús, son precisamente, sus tres resurrecciones de muertos. La de la hija de Jairo, la del joven de Naín y la de Lázaro. En el contexto próximo -y como marco literario- del relato sobre la curación de la hemorroísa (Mc 5,24-b-34par), los tres primeros Evangelistas nos han transmitido la tradición sobre el primer signo anastasiológico de Jesús o su resurrección de la hija de Jairo:

Mt 9,18-19.23-26

Mientras les decía esto,

de improviso viniendo un jefe
Mc 5,21-24a. 35-43 Apenas había pasado Jesús de nuevo en barca a la otra orilla, acudió a él mucha gente, y estaba junto al mar (v. 21).

$\mathrm{Y}$ viene uno de los jefes de la sinagoga llamado Jairo $y$,

$$
\text { Lc 8,40-42a.49-56 }
$$

$\mathrm{Y}$ sucedió que, al volver Jesús, le acogió la gente, pues estaban esperándole (v. 40).

$\mathrm{Y}$ en esto vino un hombre llamado Jairo, que era un Jefe de la sinagoga

* Además de los comentarios (infrà), Cf.: A. Loisy, Les Évangiles Synoptiques, I, Ceffonds. 1907, 812-14. 821-26; R. Bultmann, Die Geschichte der synoptischen Tradition (FRLANT 29), Tübingen ${ }^{6} 1964,228-30$; H. van der Loos, The miracles of Jesus (Suppl. NT 9), Leiden 1965, 567-73; M.-É. Boismard, Sinopsis de los cuatro Evangelios, II, Bilbao 1977, 194-97; A. Suhl, Die Wunder Jesu: "Der Wunderbegriff im Neuen Testament", Darmstadt 1980, 464-509: 464-80; G. Rochais, Les récits de résurrection des morts dans le Nouveau Testament (Soc NTSt Ms 40), Cambridge 1981, 39-112; R. Latourelle, Miracles de Jésus et théologie du miracle, Montréal-Paris 1986, 146-52 (bibliogr.). Más bibliografía sobre cada relato evangélico indicamos en las páginas siguientes (Notas 1.29.39). 
se postra ante él, diciendo:

“iMi hija acaba de morir, pero ven a imponerle las manos y vivirá!" (v. 18). Y, levantándose Jesús, le seguía con sus discípulos (v. 19)... [tras la curación de la hemorroísa],

y, llegado a la casa del jefe, viendo los flautistas y la gente alborotada (v.23), decía: “'Retiraos; pues

no murió la niña, sino duerme!". Y se burlaban de él (v. 24.) Pero, tras haber sido echada la gente,

entrando tomó la niña de la mano

$y$ ella se levantó (v. 25)

$Y$ se extendió la fama del hecho por toda aquella región (v. 26). viéndole, cae a sus pies $(v, 23)$ y le suplica instantemente, diciendo: "Mi hija está al fin de vida! ¡Ven a imponerle las manos, para que se salve y viva!" (v. 24). Y se fue con él (v. 24a)... [Tras la curación de la hemorroísa] llegan de casa del arquisinagogo, diciendo: "Tu hija ha muerto, ¿para qué molestar al Maestro? (v. 35). Pero Jesús, oído lo dicho, dice al arquisinagogo: " "No temas, sólo cree!" (v. 36). Y no dejó seguirle a nadie, sino a Pedro y Santiago y Juan, hermano de Santiago (v. 37). Y llegan a la casa del arquisinagogo, y ve el alboroto y los que lloraban y plañían (v. 38); y entrando, les dice: “ ¿Por qué alborotáis y lloráis? 'La niña no murió, sino duerme!" (v. 39). Y se burlaban de él. Pero él, echándolos a todos, lleva consigo al padre de la niña y a la madre y a los que (iban) con él; y entra donde estaba la niña (v. 40). y, tomando la mano de la niña, le dice: "TALITHÁ KOÚM!", que significa: "JOVENCITA, TE LO DIGO, LEVANTATE!" (v. 41). $Y$ al instante se levantó la jovencita y caminaba, pues tenía doce años (v. 42). Y de repente quedaron fuera de sí con gran asombro; y les mandó encarecidamente que nadie lo supiese, y dijo se le diese de comer (v. 43). $\mathrm{y}$, postrándose a los pies de Jesús, le rogaba que entrara en su casa (v. 41), pues tenía una hija única - de unos doce años-y estaba muriendo (v. 42a).... [Tras la curación de la hemorroísa], mientras él aún hablaba llega uno de casa del arquisinagogo diciendo: "Murió tu hija, no molestes ya al Maestro" (v. 49). Oyéndolo Jesús, le respondió: "!No temas, sólo cree y se salvará!" (v. 50). Llegado a la casa, no dejó entrar con él a nadie, sino a Pedro y Juan y Santiago, y al padre de la niña y a la madre (v. 51). Lloraban todos y plañían, pero él dijo: "No lloréis; pues no murió, sino duerme!" (v. 52). Y se burlaban de él, sabiendo bien que había muerto (v. 53).

Él, tomándola de la mano, alzó la voz diciendo:

“iNIÑA, LEVANTATE!” (v. 54). Y tornó a ella su espíritu, y se levantó al instante; y ordenó que se le diera de comer (v. 55). $Y$ quedaron fuera de sí sus padres, pero él les ordenó que a nadie anunciasen lo sucedido (v. 56). 
La misma sinopsis del triple relato evangélico muestra ya que las redacciones de Mt y Lc siguen a la de su fuente literaria (Mc). No sin modificarla ligeramente con propios datos estilísticos (Cf. infra) y, sobre todo, abreviándola Mt más que Lc. ¿Qué interpretación teológica envuelve la redacción literaria de cada Evangelista? ¿Late tras ésta una tradición pre-redaccional o primitiva, que se remonte al evento mismo del Jesús histórico? Y, en caso afirmativo, ¿qué mensaje salvífico reveló Él fácticamente con este primer signo anastasiológico? A estos interrogantes intentan responder los siguientes análisis histórico-tradicionales de la reproducida perícopa evangélica.

\section{1) La redacción evangélica}

El relato de cada Evangelista refleja - como veremos- claros indicios objetivos de su propia redacción literaria del evento narrado - contexto, vocabulario y estilo, composición interna-, tras los cuales debemos intentar descubrir su intencionalidad doctrinal o su interpretación teológica.

a) El evangelista MARcos nos ofrece el relato más amplio y, sin duda, el más antiguo ${ }^{1}$. Su redacción literaria está determinada ya por el contexto remoto y próximo: Tras el relato sobre la liberación exorcística del "endemoniado" geraseno (Mc 5,1-20) y enmarcando el de la curación de la hemorroísa (Mc 5,24b-34), narra el evento anastásico de Jesús (Mc 5,21-24a. 3543). Lo hace, por lo demás, imprimiendo las huellas de su vocabulario $y$ estilo ${ }^{2}$. Pues si característicos de su vocabulario son los verbos "érchesthai" + "érchontai" ${ }^{3}$, los adverbios "euthys" ${ }^{4}$ y "pollá" 5 así como la expresión "ho estin" ", a su estilo pertenecen tanto la construcción paratáctica (="kai")

1. Para su análisis, además de los comentarios (M.-J. Lagrange, 138-46; E. Lohmeyer, 99109: 104ss; V. Taylor, 285-88. 293-98: trad. españ., 328-32. 338-44; R. Pesch, I 295-314; J. Gnilka, I 209-12. 216-21). Cf.: K. Kertelge, Die Wundererzählungen im Markusevängelium, München 1970 110-20: 115ss; L. Schenke, Die Wundererzählungen des Markusevangeliums, Stuttgart 1975, 196-216: 213ss; M.-E. Boismard, o.c., 194s; A. Suhl, e.c., 470-75; G. Rochais, o.c., 54-73; R. Latourelle, o.c., $147 \mathrm{~s}$.

2. Cf. J. C. Hawkins, Horae synopticae; Oxford 1909 (reprod. 1968), 10-15. 114-53; M.-J. Lagrange, Marc, LXVII-CVI; M. Zerwi Ck, Untersuchungen zum Markus-Stil, Rom 1937; V. Taylor, Mark 2, 44-66 (trad. españ., 67-88); M. Reiser, Syntax und Stil des Markusevangeliums (WUNT 11), Tübingen 1984.

3. Mc 5,22. 35. 38 [Mc 25, Mt 3, Lc 1]: Cf. J.C. Hawkins, o.c., 12. 34; M.-J. Lagrange, o.c., LXVIII.

4. Mc 5,42ab [Mc 42, Mt 18, Lc 7]: Cf. J. C. Hawkins, o.c., 12; M.-J. Lagrange, l.c.

5. Mc 5,23. 38. 43 [Mc 9, Mt 0, Lc 0]: Cf. J. C. Hawkins, o.c., 13. 35; M.-J. Lagrange, l.c.

6. Mc 5,41. [Mc 6, Mt 0, Lc 0]: Cf. J. C. Hawkins, o.c., 13. 34; M.-J. Lagrange, l.c. 
y el presente histórico ${ }^{7}$, como el uso de pleonasmos ${ }^{8} \mathrm{y}$ de asíndeton ${ }^{9}$, de los frecuentes participios ${ }^{10} \mathrm{y}$ de la negación redoblada ${ }^{11}$, del "hóti" recitativo ${ }^{12} \mathrm{y}$ del plural impersonal ${ }^{13}$, de semitismos ${ }^{14} \mathrm{y}$ de la traducción de vocablos arameos ${ }^{15}$, siendo asimismo característico suyo la súplica de curación ${ }^{16} \mathrm{y}$ el mandato de silenciar el evento ${ }^{17}$. ¡Una profunda impronta literaria del Evangelista refleja, pues, el relato marciano! Y si su unidad literaria está garantizada por la explícita o implícita mención de los tres protagonistas —Jesús, el "arquisinagogo" y su "hija" - desde el principio hasta el fin, la unidad temática viene dada por la progresiva tensión dinámica entre los tres estados de aquélla: Quien estaba "al fin de vida" (v. 23) y luego "murió" (v. 35), a la orden de Jesús "se levantó" o resucitó y "caminaba" (vv. 41-42) ${ }^{18}$. Así redactó Marcos la parte central del relato. Introducido todo él por la inicial situación del lugar (v. 21), y concluido con el efecto del prodigio en los circunstantes así como con el doble precepto de Jesús: Silenciar aquél y "dar de comer" a la resucitada (v. 43). La estructura literaria de la narración marciana ${ }^{19}$ es pues clara:

\section{-Introducción (v. 21)}

-El relato anastasiológico (vv. 22-24a. 35-42)

el ruego por quien "está al fin de la vida" (vv. 22-24a)

disuasión ante la muerte de la enferma e invitación a la fe (vv. 35-37)

disuasión al "arquisinagogo" (v. 35)

exhortación de Jesús a seguir creyendo (v. 36)

selección de los tres discípulos-testigos (v. 37)

la resurrección de la difunta por Jesús (vv. 38-42).

7. Mc 5,21-24. 35-43 (passim!): Cf. J.C. Hawkins, o.c., 150-52. 143-48; M.-J. Lagrange, o.c., LXIXs; M. Zerwick, o.c., 1-21. 49-57; V. Taylor, o.c., 46-49 (trad. españ., 69. 71).

8. Mc 5,39a: Cf. J. C., Hawkins, o.c., 139-42; M. J. Lagrange, o.c., LXXIIs; V. Taylor, o.c., 50s. (trad. españ., 73).

9. Mc 5,39b: Cf. J. C., Hawkins, o.c., 137; M. J. Lagrange, o.c., LXX-LXXII; M. Zerwick, o.c., 21-23; V. Taylor, o.c., 49 (trad. españ., 72).

10. Mc 5,23. 35. 36. 38. 39. 40. 41: Cf. M. J. Lagrange, o.c., LXIX; V. Taylor, o.c., 46 (trad. españ., 68s.).

11. Mc 5, 37: Cf. M. J. Lagrange, o.c., LXIII; V. Taylor, o.c., 46 (trad. españ., 69).

12. Mc 5,23. 35: Cf. M. Zerwick, o.c., 41s.

13. Mc 5,35: Cf. V. Taylor, o.c., 47 (trad. españ., 70).

14. Mc 5,42b. 43b: Cf. M. J. Lagrange, o.c.; LXXXIV-CVI; V. Taylor, o.c., 55-66 (Trad. españ., 77-88).

15. Mc 5, 41; Cf. 15,22. 34 .

16. Mc 5,23par; Cf. 1,40par; 6,56par; 7,25. 32; 8,22; 10,47; M. Zerwick, o.c., 26s. Característico de Mc es asimismo el ruego con el verbo "parakaléin" (Mc 5,23 [Lc 8,41]; 1,40; 6,56 [Mt 14,36]; 7,32; 8,22; Cf. 5,10 [=Lc 8,31]. 12par. 17 [=Mt 8,34]. 18), y la "imposición de las manos" por Jesús: Mc 5,23 (=Mt 9,18); Cf. 6,5; 7,32; 8,23. 25.

17. Mc 5,43a ("diesteílato")=7,36a. b; 9,9: Cf. M. Zerwick, o.c., 25s; V. Taylor, o.c., 122-24 (trad. españ., 137s); G. Minette de Tillesse, Le secret messianique dans l'Évangile de Marc (LD 47), Paris 1968, espec. 39-73 ("les récits des miracles").

18. Cf. Rochais, o.c., 55.

19. Cf. E. Lohmeyer, o.c., 104 (el relato de Mc "ist kunstvoll gegliedert"); G. Rochais, o.c., 54s. 
¿muerta o dormida? (vv. 38-40a)

los cinco testigos del prodigio (v. 40b)

EL EVENTO ANASTÁSICO (vv. 41-42)

gesto y mandato anastásico de Jesús (v. 41)

obediencia inmediata de "la jovencita" (v. 42)

-Conclusión (v. 43): Efecto del prodigio en los circunstantes (v. 43a) y doble precepto de Jesús (v. 43b.c).

A la luz de esta marcada redacción literaria del evangelista Marcos, claro indicio de que "el evangelio sobre Jesucristo-el Hijo de Dios" (Mc 1,1) alcanza aquí una elevada meta-, no es difícil detectar su interpretación teológica del evento. Ya el contexto remoto y próximo del relato marciano (Cf. supra) delata la intencionalidad de presentar a Jesús como el Vencedor de la triple esclavitud radical: De Satanás (="endemoniado" geraseno), de la enfermedad (=hemorroísa) y de la muerte (=hija de Jairo). La victoria sobre ésta constituye por cierto el centro focal del relato. La ya creyente súplica humilde del "arquisinagogo" Jairo a Jesús - cae a sus pies"_, en favor de la que "está al fin de la vida", fue aceptada sin ambages por quien efectivamente "se fue con él" a otorgarle el favor suplicado: Consciente, por tanto, de poder conservar la vida e impedir la muerte de aquélla o ser el Señor de la vida y de la muerte. Como tal se manifiesta luego y más claramente Jesús. A la disuasión formulada al Padre, ante la muerte de su "hija", contrapone "el Maestro" su exhortación a "no temer" por este mortal evento y "únicamente seguir creyendo" o apoyándose en su poder suplicado: "iLa niña no murió, sino duerme" tan sólo ante el poder divino de quien considera la muerte tan pasajera como un sueño $\mathrm{y}$, por tanto, le es tan fácil resucitar a un muerto como despertar a un dormido! ${ }^{20}$. Ese dominio sobrehumano de Jesús sobre la muerte acentúa Marcos en su relato de prodigio. Aquél lo realiza, -tras "entrar" en la alcoba de la muerta con los cinco testigos elegidos-, no invocando el revivificante poder de Dios o del exclusivo Agente de la resurrección corporal ${ }^{21}$, sino con un sencillo gesto personal - "tomando de la mano a la niña"- y un también personal —"te lo digo"— imperativo anastásico: "Talithá koum!=¡Jovencita, levántate!". Cuyo resurreccional efecto no se demoró, pues "al instante se levantó" aquélla "y caminaba". Aquí culmina el

20. Así con algunos comentaristas (E. Lohmeyer, 106s; R. Pesch, 308; J. Gnilka, 217) y los estudios de K. Kertelge, o.c., 116. 118; L. Schenke, o.c., 210; Cf. G. Rochais, o.c., 65. Puesto que la niña "había muerto" (Mc 5,35), el Jesús marciano no pudo expresar con el "sueño" (Mc 5,39), de aquélla "una muerte aparente": Contra V. Taylor, o.c., 295: trad. españ., 342 (y otros autores ahí citados).

21. Tal era la concepción veterotestamentaria y judaica: Cf. S. Sabugal, La fe de Israel en la resurrección de los muertos: RevAg 29 (1988) 69-128: 125; La fe del Judaísmo antiguo en la resurrección de los muertos: Ib. 30 (1989) 143-54: 150s. 
relato anastásico de Mc. Así lo muestra ya el habernos conservado las mismísimas palabras originales de Jesús. (cf. infra), no sin traducirlas para sus lectores [=comunidad romana] ignaros del arameo galilaico: ¡Debían entender el imperativo anastásico del Maestro y arraigar así su fe en el señorío divino del Resucitado sobre los muertos! Por lo demás, el Evangelista tradujo el verbo "koum" por "egeíro" y, seguidamente, formuló la resurrección de "la jovencita" con el verbo "anístemi", dos verbos usados por Mc para expresar la resurrección de Jesús ${ }^{22}$ y la escatológica resurrección de los muertos ${ }^{23}$ : Con ello interpretó probablemente la resurrección de aquella como adelanto anastásico del poder divino desplegado por Jesús ya en su resurrección y, al final, en la de todos los muertos ${ }^{24}$. Pues una cosa, en todo caso, es clara: La muerte se sometió al mandato de quien así obró y habló, consciente de poseer y desplegar el mismo poder anastásico de Dios. Se comprende, pues, la profunda "extrañeza" o el "gran asombro" de los cinco testigos oculares, ante el divino dominio de Jesús sobre la muerte, sólo plenamente revelado con su Resurrección ${ }^{25}$. De ahí el "encarecido" precepto del Jesús marciano a que "nadie supiese esto", como se lo impuso también a los tres mismos discípulos —Pedro, Santiago y Juan-, tras la transfiguración o el anticipado evento de su Resurrección ${ }^{26}$ : ¡En ésta solamente culminó la progresiva manifestación tanto de la dignidad mesiánica y filiación divina de Jesús, como de su señorío sobre la muerte! ${ }^{27}$. Por lo demás, la conclusiva orden de Jesús a "dar de comer" o alimentar a la resucitada manifiesta la realidad de su resurrección y, a la vez, la próvida bondad del poderoso Resucitante $^{28}$. No hay, pues duda de que Marcos interpretó la tradición del evento para su comunidad cristiana — iy en ella para nosotros! - como una gradual

22. "Egeíro": Mc 14,28; Cf. 16,14 (el NT lo emplea 51x; "anístemi" Mc 6,31; 9, 9. 31; 10, 34; Cf. 16,9 (el NT lo usa 18x).

23. "Egeíro": Mc 12,26 (el NT lo usa 16x: "anístemi": Mc 12,25 (el NT lo emplea 3x). Sobre el uso de "egeiro" y "anístemi" por el NT, cf. S. Sabugal, El vocabulario anastasiológico del NT: Rev. Ag 30 (1989) 385-401: 387-89. 393-95 (bibliogr. 385).

24. Cf. infra, n. 25. Así con G. Rochais, o.c., 73.

25. La extrañeza (exéstesan) de aquéllos (Mc 5,42b; Cf. 2,12;6,51) es análoga a la de las mujeres (éxtasis) tras el anuncio de la resurrección de Jesús (Mc 16,8).

26. Mc 9,2.9. Sobre ese significado de la transfiguración, Cf. R. Pesch, o.c., II 67; S. Sabugal, Abbá, 515s.

27. Tal es el significado del "secreto mesiánico" en Mc y, concretamente, en su contexto de los milagros de Jesús: Cf. V. Taylor, o.c., 122 (trad. españ., 137); X. Léon-Dufour, Les Évangiles et l'histoire de Jesus, Paris 1963, 181-82. 383s: trad. españ., 158-59. 338s (bibliogr.); G. Minette de Tillesse, o.c., 503-6: 503s; S. Sabugal, Christós, Barcelona 1972, 132 (y passim).

28. Así con G. Rochais, o.c., 70; Cf. M.-J. Lagrange, o.c., 145; V. Taylor, o.c., 298 (trad. españ., 344). Puesto que Mc silencia la comida del Resucitado (Cf. Lc 24,41-43), la de la resucitada (Mc 5,43c) no es sólo prueba de su resurrección: Contra R. Pesch, o.c., I 311; J. Gnilka, o.c., 218. 
manifestación del divino poder anastásico de Jesús — sólo desvelado a los creyentes en Él-y como el simbólico inicio de la escatológica resurrección de los muertos. Quien, ante humanamente desesperadas situaciones de muerte, "cree" o se apoya en el señorio de Jesús sobre ésta —sólidamente atestiguado por los cinco testigos de aquel evento-, "no teme" ya su espectro; pues, si con Él "entra" en aquellas situaciones mortales, experimentará sin tardar su poder anastásico y, tras la muerte, "se levantará" o resucitará de su "sueño" al imperioso mandato de Quien -como a la hija de Jairo-le dirá: "¿Levántate!".

b) El evangelista LuCAS ofrece un relato más breve que el de $\mathrm{Mc}^{29}$. fuente de su redacción literaria. Aquél, en efecto, sigue de cerca el relato marciano. Ya en su contexto remoto y próximo: También el relato lucano (Lc 8,40-42. 49-56), precedido por el de la curación exorcística del "endemoniado" .geraseno (Lc 8,26-39), enmarca el de la curación de la hemorroísa (Lc 8,43-48). Análoga cercanía refleja el texto de Lucas respecto a su fuente, a la que sin embargo abrevia y mejora estilísticamente, corrije o modifica y en ocasiones amplía ${ }^{30}$. ¿Las variantes textuales más abultadas de Lucas? Por su "hija única", que "murió", suplica Jairo a Jesús (v. 42), convencido, sin duda, de poder resucitarla o renovar el prodigio anastásico, por él hecho en Naín con el "hijo único" de una viuda ${ }^{31}$. A la disuasión, ante el estado mortal ("téthneken") o muerte real de "su hija" (v. 49), contrapone Jesús la invitación: "¡No temas, sólo cree y se salvará" (v. 50) de la muerte! A Jairo se le exige, pues, el salto a la fe "en el Señor Jesús", que opera "la salvación" radical $^{32}$, incluida la de la muerte. Pues su hija "no murió, sino duerme" (v. 52) tan sólo para quien es el Señor de la muerte: ¡Eso es Jesús! Y lo muestra,

29. Para su análisis, además de los comentarios (M.-J. Lagrange, Luc 252-53. 255s; W. Grundmann, Lukas 182-84; H. Schürmann, Lukas 489-90. 492-97; I.H. Marshall, Luke 341-44. 346-48; J.A. Fitzmyer, Luke I 742-46. 748-50), Cf. los estudios de: U. Busse, Die Wunder des Propheten Jesu, Stuttgart 1977, 219-31; M.-É. Boismard, o.c., 195. A. Suhl, e.c., 477-80; G. Rochais, o.c., 74-87; R. Latourelle, o.c., 148s.

30. En sintonía con las características literarias de Lc (Cf. J.C. Hawkins, o.c., 15-29. 35-51. 174-97; H.J. Cadbury, The Style and literary method of Luke, Cambridge 1920; A. Plummer, Luke, XLI-LVII; M.-J. Lagrange, Luc, XCV-CXXVIII. J.A. Fitzmyer, Luke I 109-14), su relato evita la parataxis de Mc con la partícula "de" (vv. 51. 52. 56: Cf. H.J. Cadbury, o.c., 142s) y omite los adv. marcianos "pollá" y "euthús" (vv. 41. 52. 55: Cf. H.J. Cadbury, o.c., 199); introducido aquél con la construcción lucana "kai idoú... anér" (v. 41: Cf. J.C. Hawkins, o.c., 16; H.J. Cadbury, o.c., 178. 189; A. Plummer, o.c., LXI; M.-J. Lagrange o.c., XCIC), sustituye "onómati" (Mc) por "ho ónoma" (v. 41: Cf. C.J. Kawkins, o.c., 21. 44), añadiendo el pron. indefinido "tis" (v. 49: Cf. H. J. Cadbury, o.c., 193) y el generalizante "pántes" (v. 52: Cf. H. J. Cadbury, o.c., 115). Éstos y otros datos reflejan claramente la redacción literaria del texto marciano por Lc: Así lo ha mostrado brillantemente G. Rochais, o.c., 74-83.

31. Lc 7,11-17 (vv. 14-15): Cf. S. Sabugal, "jJoven, te lo digo, levántate!" (Lc 7,11-17). Análisis histórico-tradicional: EstAg 23 (1988) 469-82.

32. Act 16,31 ; Cf. 14,$9 ; 15,11$; Lc 7,$50 ; 8,48 ; 17,19 ; 18,42$. Muy bien subrayado por: W. Grundmann, o.c., 183; G. Rochais, o.c., 78. 
superando la incrédula "burla" de quienes "sabían bien que había muerto" (v. 53) con el imperioso grito anastásico: "¡NIÑA, LEVÁNTATE!" (v. 54); un grito del todo análogo al dirigido por "el Señor" compasivo al difunto "hijo único" de la viuda: "¡Joven, te lo digo, levántate!" (Lc 7,13-14). El efecto inmediato de aquel grito, semejante al del niño resucitado por Elías tras "invocar" a Dios, fue que "tornó a ella su espíritu (Cf. $1 \operatorname{Re} 17,21$ s) y se levantó enseguida" (v. 55a) o resucitó realmente, como lo muestra el mandato de Jesús a "darle de comer" (v. 55b) ${ }^{33}$. Así hace culminar Lucas la parte central de su relato (vv. 41-42. 49-55), cuya unidad literaria y temática viene dada por la marcada contraposición entre la "muerte" real de la "hija" de Jairo (vv. 41-42. 49) y su verdadera "salvación" o "resurrección" por Jesús (vv. 50-55). La "extrañeza de los padres" ante el prodigio anastásico y la orden de.Jesús a silenciarlo (v. 56) concluye al relato lucano, introducido con la mención del anhelado acogimiento de Jesús por "la gente" (v. 40). Su estructura literaria ${ }^{34}$ diverge, pues, algo, respecto a la de Mc (Cf. supra):

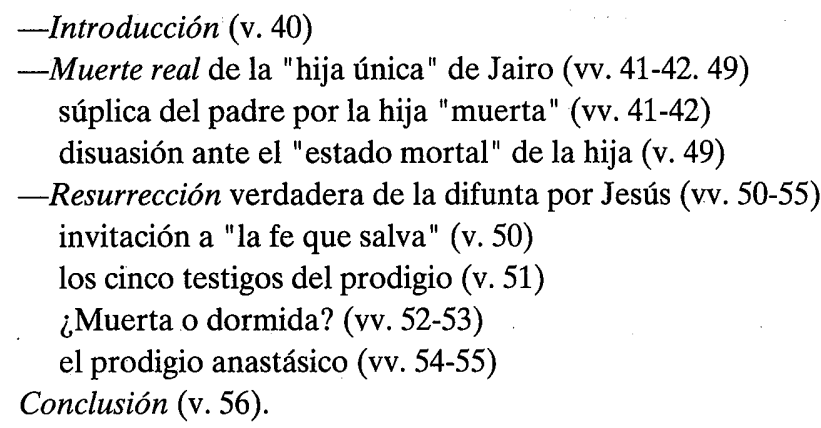

Estos desarrollos sobre la redacción lucana de su fuente literaria (Mc) permiten detectar ya la interpretación teológica del evento por Lucas ${ }^{35}$, para sus lectores. A quienes, por lo demás, no les es del todo nuevo este prodigio anastásico de Jesús. Aquéllos, en efecto, saben ya que "el Señor" resucitado y objeto de la fe cristiana "resucitó" con propio poder divino al "joven" de Naín y, con este signo anastásico inauguró la preanunciada "resurrección" escatológica de "los muertos" 36. ¡Jesús es el Señor de la muerte y de los muertos! Esto confiesa el presente relato lucano. Ya en el contexto remoto y próximo (Cf. supra) resalta Lucas su doble victoria sobre la esclavitud radical,

33. Cf. Lc 24, 41-43; Act 1,4; 10,40-41. Así con H. Schürmann, o.c., 495; I. H. Marshall, o.c., 348; G. Rochais, o.c., 82.

34. Cf. U. Busse, o.c., 224s.

35. Cf. U. Busse, o.c., 226-30; G. Rochais, o.c., 86s.

36. Lc 7,13 ("el Señor") 14. 19 ("el Señor"). 22: Cf. S. Sabugal, La embajada mesiánica de Juan Bautista, Madrid 1980, 83-114: 91s; Id., a.c., 472. 
impuesta por Satanás (="endemoniado" geraseno) y la enfermedad (="hemorroísa). Ahora el Evangelista subraya el señorío divino de Jesús ' sobre la muerte. Pues quien "murió" y "estaba muerta" realmente "se salvará" de la muerte, si su padre "sólo cree" o se apoya en el divino poder anastásico de Jesús o "el Señor" (Cf. Act 16,31), para quien la difunta sólo "duerme" o la muerte es sólo un sueño: ¡Él es el Salvador y el Señor de la muerte! Este señorío divino desplegó Jesús: Sin invocar previamente a Dios, como lo hizo Elías, resucitó a la realmente difunta con el solo imperio de su voz: "¡Levántate!" y, con este signo anastásico, inauguró la escatológica resurrección de los muertos ${ }^{37}$. Es, pues, mayor que Elías o el gran taumaturgo veterotestamentario quien, por lo demás, se atribuyó el mismo poder anastásico del "Dios que resucita a los muertos" ${ }^{38}$. En la interpretación lucana Jesús es, pues, el compasivo y poderoso "Señor" de los muertos así como el Salvador de la muerte, señorío y salvación experimentados por quienes creen en él o se apoyan en su divino poder anastásico.

c) Diversa es la interpretación del evento por el evangelista MATEO, para su comunidad judeo-cristiana ${ }^{39}$. La redacción literaria de aquél sigue a su fuente $(\mathrm{Mc})$, abreviándola considerablemente y, en ocasiones, modificándola ${ }^{40}$. Diverso es ya el contexto del relato mateano. Éste se inserta en el vasto contexto remoto de la segunda sección de su evangelio (Mt 8,1-11,1), y, más concretamente, del relato sobre los diez signos mesiánicos obrados por Jesús (Mt 8-9) en correspondencia con "los diez prodigios" obrados por

37. Lucas formula esta resurrección final (Act 26,8; Lc 20,37; Cf. 11,31) con el mismo verbo [="egéiro"] que en la resurrección de la hija de·Jairo $(\operatorname{Lc} 8,54)$ y en la respuesta de Jesús a los discípulos de Juan Bautista sobre la ya inaugurada resurrección de "los muertos" (Lc 7,22).

38. Act 26, 8; Cf. Lc 20, 37-38.

39. Para su análisis, además de los comentarios (M.-J. Lagrange, Matthieu 185; P. Bonnard, Matthieu 134-36: trad. españ. 211-14; W. Grundmann, Matthäus 273-76; J. Gnilka, Matthäus I 339-43), Cf. los estudios de: H.J. Held, Matthäus als Interpret der Wunder Jesu: Überlieferung und Auslegung im Matthäusevangelium." (WMANT 1), Neukirchen-Vluyn ${ }^{4} 1965,153-287$ : 16871; M.-É. Boismard, o.c., 194; A. Suhl, e.c., 475-77; G. Rochais, o.c., 88-99; R. Latourelle, o.c., 149.

40. En conformidad con las características literarias de Mt (Cf. J. C. Hawkins, o.c., 3-10. 3035. 154-73; M.-J. Lagrange, Matthieu, LXXI-CVII; U. Luz, Das Evangelium nach Matthäus, I (EKK, I. 1), Neukirchen-Vluyn 1985, 31-56; W. Schenk, Die Spache des Matthäus, Göttingen 1987), su relato abrevia el de Mc (Cf. J. C. Hawkins, o.c., 158-60) y lo modifica: Introducciéndolo con la partícula "idoú" (v. 18: Cf. J. C. Hawkins, o.c., 5. 31; M.-J. Lagrange, o.c., CIIs; W. Schenk, o.c., 296-98), sustituyendo "cae a sus pies" por "le adora" (proskynei, v. 18: Cf. J. C. Hawkins, o.c., 7; G. Rochais, o.c.,91; .W. Schenk, o.c., 421-23) y "no lloréis" por "retiraos" (anachoréite, v. 24: Cf. J. C. Hawkins, o.c., 4; W. Schenk, o.c., 27s), no sin añadir el adv. "árti" (v. 18b: Cf. J.C. Hawkins, o.c., 4; M.-J. Lagrange, o.c., CI; W. Schenk, o.c., 49s) y el participio "egerthéis" (v. 19a: Cf. J. C. Hawkins, o.c., 5. 30; G. Rochais, o.c., 92; W. Schenk, o.c., 209). Todos éstos y otros indicios reflejan la redacción del relato de Mc por Mt: Cf. G. Rochais, o.c., 89-97. 
Moisés en Egipto ${ }^{41}$, siendo aquéllos "las obras del Mesías" que actualizan "las obras de Dios" o sus preanunciadas gestas salvíficas, entre las que se cuentan la escatológica resurrección de "los muertos" 42: Mayor que Moisés es Jesús o el nuevo Libertador mesiánico, pues con sus signos liberadores realizó "las obras de Dios". Esa dignidad mesiánico-divina de Jesús resalta el contexto próximo del relato mateano: Tras su enseñanza (v. 18a) sobre la necesidad de acoger de forma nueva — "odres nuevos" - la novedad de su mensaje - "vino nuevo" - salvífico (Mt 9,14-17), sigue el unitario relato de tres milagros (Mt 9,18-31) o signos mesiánicos, -la curación de la hemorroísa y la resurrección de la "hija" del "jefe" así como la curación de "dos diegos"-, claramente relacionados entre sí por el tema de la fe (vv. 18. 21-22. 28-29) y por la conclusiva "divulgación" de dos de aquéllos "en toda la región" (vv. 26.31) ${ }^{43}$. Por lo demás, el texto mateano abrevia y modifica al de Mc. Un "jefe" anónimo - a Mt no le interesa el nombre ni la profesión, sino su cualidad o actitud ante Jesús - se acerca y, "postrándose ante" Jesús o adorando al Señor ${ }^{44}$, le suplica imponer "su mano sobre su hija apenas muerta", seguro de que con ello "vivirá" (v. 18b): ¡Tal fe tiene aquél, en el poder anastásico de Jesús o del Señor sobre la muerte! A lo que Él no resiste: Le sigue con sus discípulos" (v. 19). Y, "llegando a la casa del jefe", tras arrojar a "la gente" incrédula (vv. 23-25a) "tomó la mano de" la difunta y con sólo ese gesto- "se levantó la niña" (v. 25b) o resucitó ${ }^{45}$. El marcado paralelismo textual entre la súplica del "jefe" y el gesto anastásico de Jesús (vv. 18b. 25b) refleja ya la unidad literaria y temática de todo el relato mateano, - la fe de aquél en el vivificante poder de Éste logró la resurrección de su hija-, introducido por el enlace literario con la previa enseñanza de Jesús (v. 18a) y concluido con la "divulgación" del evento "por toda aquella región" (v. 26). La estructura literaria del "muy bien compuesto" relato mateano ${ }^{46}$, es pues clara:

-Introducción (v. 18a)

—Mesiánico signo anastásico de Jesús (vv. 18b-25) suplicante fe en el poder del Señor sobre la muerte (vv. 18b-19a) anastásica satisfacción de la súplica (vv. 23-25) expulsión de "la gente" incrédula (vv. 23-25a)

41. Aboth 5,5: Cf. S. Sabugal, o.c., (La embajada), 35. 47s; W. Grundmann, o.c., $245 \mathrm{~s}$.

42. Mt 11,2.5=Is 26, 19. 23: Cf. S. Sabugal, o.c., 41-42. 63-65.

43. La unidad literaria de Mt 9,18-31 es subrayada por G. Rochais, o.c., 97s.

44. Ese significado tiene generalmente "prosekynein" [=Mt 13, Mc 2, Lc 2] en Mateo: Mt 28,9.17; 14,33; Cf. 2,2. 8. 11; una "adoración" divina: Cf. Mt 4,10; 18,26.

45. "Egérthe": Con este verbo formula Mt tanto la resurrección de Jesús (Mt 28,6.7; Cf. 16,$21 ; 17,9.23 ; 20,19 ; 26,32 ; 27,63$. 64) como la escatológica resurrección de "los muertos" (Mt 12,42 ), inaugurada en los signos anastásicos de Jesús (Mt 11,5). 
el gesto anastásico de Jesús (v. 25b)

Conclusión (v. 26)

Esa redacción literaria del relato marciano por el Evangelista Mateo refleja ya su interpretación teológica del evento narrado ${ }^{47}$. Dos temas estrechamente relacionados- recorren todo el relato mateano: el cristológico y el de la fe. El contexto remoto (Cf. supra) muestra que el Evangelista interpretó ese evento anastásico como una de "las obras del Mesías" o un signo mesiánico de Jesús, con el que se reveló ser mayor que Moisés al realizar una de "las obras de Dios" o inaugurar la preanunciada resurrección escatológica de "los muertos": ¡Quien así obra, con el anastásico poder del mismo Dios, es el Señor de la muerte! Nada de extraño, pues, si como Señor es adorado por el "jefe" y, desplegando un poder divino, resucitó luego a su difunta hija con el solo gesto anastásico de su mano, poderosa para "despertar" a la "dormida" o resucitar a la muerta como salvíficamente poderosa se mostró "la mano" de Dios en favor de su pueblo ${ }^{48}$ : "Se levantó" o resucitó la difunta, sometiéndose así a Jesús la muerte. En su anastásico poder divino se apoyó, por cierto, la creyente súplica de aquél: $\mathrm{Su}$ "hija muerta" resucitará o "vivirá", si Él "le impone su mano". Como la hemorroísa y los "dos ciegos" fueron curados por Jesús a causa de "su fe" (vv. 22. 29s), también el ruego del anónimo "jefe" refleja una fe grandísima o firmemente sólida en el poder de Jesús sobre la vida y en su señorío sobre la muerte ${ }^{49}$, posteriormente corroborado con su divino gesto anastásico: La creyente súplica de aquél logró lo humanamente irrealizable y quedó satisfecha. Esto subraya el evangelista, presentando por tanto al "jefe" como un modelo de la fe sólida en Jesús y haciendo de su relato una instrucción sobre la fe o, más exactamente, sobre el alcance de la fe cristiana en el poder anastásico del Señor resucitado ${ }^{50}$, franqueando incluso aquélla la barrera de la muerte. Es, pues, claro: El relato de Mc devino en la interpretación mateana una enseñanza cristológica sobre el divino poder anastásico de Jesús o el mesiánico Señor, quien con su resurreccional signo inauguró la escatológica resurrrección de los muertos o realizó. una de "las obras de Dios", siendo el relato de Mt a la vez una instrucción sobre lo que puede alcanzar la fe de los que -como el paradigmático "jefe"-en situaciones de muerte se apoyan en Jesús o el Señor resúcitdo, a quien "le fue consignado todo poder en el cielo y en la tierra" (Mt $28,18)$.

46. Cf. G. Rochais, o.c., 89.

47. Cf. G. Rochais, o.c., 97-99; J. Gnilka, o.c., 342s.

48. Éx 7,4; 9,3; Dt 3,24; 4,34; 5,15; 6,21; 7,8; Sal 136, 11-12 etc: Así con J. Gnilka, o.c., 342.

49. Muy bien subrayado por varios autores: P. Bonnard, o.c., 135 (trad. españ., 212); W. Grundmann, o.c., 274; H. J. Held, e.c., 169; G. Rochais, o.c., 91s; J. Gnilka, o.c., 340.

50. Así con H. J. Held, e.c., 170; W. Grundmann, o.c., 273; G. Rochais, o.c., 97-99; J. Gnilka, o.c., $342 \mathrm{~s}$. 
Resumiendo estos desarrollos: la redacción literaria de los tres Evangelistas responde a su peculiar interpretación del evento como un momento culmen de la gradual manifestación de la dignidad mesiánica y filiación divina de Jesús (Mc), un poderoso y compasivo gesto del Señor de los muertos y Salvador de la muerte (Lc), una instrucción sobre el alcance de la fe en el mesiánico y divino poder anastásico del Señor (Mt); los tres Redactores evangélicos coinciden sin embargo en interpretar el evento como un signo del divino poder anastásico de Jesús y, a la vez, como inauguración de la escatológica resurrección de los muertos. ¿Late, tras esta interpretación común, una tradición pre-redaccional?

\section{2) La tradición evangélica}

Las redacciones de Mt y de Lc fueron elaboradas sobre su fuente literaria o el más antiguo relato de Mc. Objetivos indicios literarios, sin embargo, muestran que este Evangelista redactó e interpretó a su vez una tradición cristiana (Cf. infra). ¿Puede ser individuada a) la extensión literaria y b) la interpretación teológica del evento, a este nivel o estadio de la tradición preredaccional? ${ }^{1}$.

a) Todo el relato de Mc está recorrido por el insistente uso de la partícula "kai" o su característica construcción paratáctica ${ }^{2}$; la cual, en muchos casos, puede ser "influjo" de la tradición aramea del relato, pues dicha construcción "es mucho más frecuente en arameo que en griego" ${ }^{3}$. A ese nivel tradicional, por lo demás, se remontan muchos datos del relato marciano sobre la súplica del arquisinagogo a Jesús (Mc 5,22-24). Instructivo, a este respecto, es el marcado paralelismo literario entre el relato marciano y un texto del qumránico "Apócrifo del Génesis" (XX 21s) sobre la súplica, que un noble de la corte faraónica dirigió a Abraham por la curación del "rey" de Egipto ${ }^{4}$ :

"Y viene Jairo [a Jesús] ...y le suplica... que viniendo le imponga las manos, a fin de que sea curada y viva
"Entonces Hornaquósh vino a mí [=Abraham] y me suplicó venir ...e imponerle [=faraón] mis manos, a fin de que él viva".

El evidente paralelismo textual muestra que Mc redactó probablemente su relato sobre una tradición cristiano-palestinense de aquella súplica. Lo que

1. A este respecto, Cf.: M.- Boismard, o.c., 196s; R. Pesch, Markus, I 212-13; R. Rochais, o.c., 100-112. Una exposición y crítica de la complicada teoría de M.-E. Boismard ofrece G. Rochais, o.c., 100-4.

2. Así lo subrayan todos los estudios sobre el vocabulario y estilo de Mc: Cf. supra, n.2.

3. M. Black, An aramaic approach to the Gospels and Acts, Oxford ${ }^{31967,61-69: 61.69 .}$

4. Cf. G. Rochais, o.c., 58. 104 
varios indicios de ésta corroboran. Ya el mismo nombre original de "Jairo" 5 , sólo aquí usado por Mc (v. 22) pero conocido en la literatura veterotestamentaria y judeo-palestinense ${ }^{6}$, "parece remontarse a una tradición anterior a Mc y, sin duda, a la primera tradición [aramaica] del relato" 7 . A esa pertenece asimismo la profesión religiosa de aquel - "uno de los arquisinagogos" - y la no marciana expresión "cae a sus pies" ${ }^{8}$ así como el ruego (="parakaléi") de Jariro 9, "diciendo que" ${ }^{10}$ su hija "está al fin de su vida ${ }^{11}, \mathrm{y}$ suplicando a Jesús "que, viniendo, le impusiese ${ }^{12}$ las manos ${ }^{13}$, para que se salve y viva" ${ }^{14}$; tras cuyo ruego, Jesús "partió con él" ${ }^{15}$. También el relato marciano sobre la superada disuasión del arquisinagogo por la invitación de Jesús a la fe (Mc 5,35-37) refleja muchos datos de su tradición aramaica: Los reiterados semitismos del v. $35^{16}$ traslucen las "huellas de un modelo arameo" ${ }^{17}$; a cuya tradición también se remontan sin duda tanto la construc-

5. Para la crítica textual, Cf. G. Rochais, o.c., 56.

6. Núm 32,41; Jos 13,30; Jces 10,3; 1Crón 2,22s; 1Esd 5,31 (LXX); Est 2,5; Fl. Josefo, Bell. Jud., II 447 (=en Massáda).

7. G. Rochais, o.c., 57.

8. Mc 5,22. Que Jairo era "uno de los arquisinagogos". (v. 22a) a la aramaica tradición o fuente de Mc (Cf. G. Rochais, o.c., 57. 106. Por lo demás, la expresión "cae a sus pies" (v. 22b) es única en Mc, quien redacta diversamente el humilde gesto del "leproso" (Mc 1,40) y del "endemoniado" geraseno (Mc 5,6): ¡No es creación de Mc! Más aún: El empleo de aquella expresión veterotestamentaria (Cf. 1Sam 25,24; 2 Sam 22,39; $2 \operatorname{Re} 4,37$ ) por la judeo-cristiana tradición joannea (Jn 11,32; Apoc 1,17) delata su tradicional origen palestinense.

9. Mc 5,23. Ese verbo es usado por los tres primeros Evangelistas y siempre en el contexto de curaciones o exorcismos de Jesús (Mc 1,40; 5,10. 12 [=Lc 8,31. 32]. 17 [=Mt 8,34]. 18. 23 [=Lc $8,41] ; 6,56$ [=Mt 14,36]; 7,32; 8,22; Mt 8,5; Lc 7,4): Se remonta por tanto a la tradición judeo-cristiana, como lo muestra su ausencia en la tradición helenístico-cristiana sobre la oración y su paralelismo con el qumránico texto mencionado (Cf. supra).

10. Expresión septuagintista (Gén 37,35; 42,14; 45,26; Éx 2,22; 3,12; Cf. Gén 40,7; Dt 7,17 etc) y traducción del hebr. "lemór"(aram. $\mathrm{l}^{\mathrm{e}}$ memár), frecuentemente usada para introducir un ruego: Cf. M. Zerwxick, Graecitas Biblica, Roma ${ }^{2} 1966,368$.

11. Esta expresión, única en Mc, es propia del griego popular: Cf. G. Rochais, o.c., 58.

12. Otra expresión única en Mc y proveniente, sin duda, de su tradición judeo-cristiana, pues "hína elthón"+subj. es una construcción aramea: Cf. M.-J. Lagrange, Marc 87; Matthieu, XCV; G. Rochais, o.c., 58. 104.

13. La curativa "imposición de las manos" fue practicada en las comunidades cristianas (Cf. Mc 16,18; Act 9,12. 17-18; 28,8), como prolongación de su habitual praxis por Jesús (Mc 6,5; 8,23. 25; Lc 4,40; 13,13) a ruego de otro (Mc 5,23 [=Mt 9,18]; 7,32); atestiguado este ruego por el qumránico texto mencionado (supra: Cf. D. Flusser, Healing throu laying-on hands in the Dead Sea Scrolls: IEJ 7 [1957] 107s; H. Braun, Qumran und das NT, I, Tübingen 1966, 89s), aquel gesto "debió existir ya en algunos círculos" del antiguo Judaísmo palestinense (H. Braum, o.c., 89): De la tradición judeo-cristiana (Cf. Act 9,12.17-18) proviene pues el testimonio de Mc.

14. Expresión única en Mc, quien la recibió sin duda de su tradición: Ésta añadió probablemente el verbo "sózein" (=salvar, curar) al original aramaico "vivir"=curar (1QGA, XX 22: Cf. M. Black, o.c., 71, n. 1), con el significado de "salvar" (Jn 3,17; 1Cor 5,5; Act 16,30; Cf. 14,9).

15. Mc 5,24a. Esa expresión, única en Mc y en todo el NT, proviene de la tradición premarciana. 
ción semítica "oyendo lo hablado" ${ }^{18}$, como el doble imperativo de Jesús: "¡no temas, sólo cree!" ${ }^{19}$, y su acompañamiento por los tres discípulos "Pedro y Santiago y Juan" ${ }^{20}$ o quienes en la comunidad jerosolimitana "eran considerados como columnas" de la Iglesia (Gál 2,9). Muchos datos substanciales del relato marciano sobre el prodigio anastásico de Jesús (Mc 5,38-42) provienen asimismo de la tradición judeo-cristiana, usada por el Evangelista: Ya la "llegada" de Jesús y sus acompañantes discípulos "a la casa del arquisinagogo" y su "visión" ${ }^{21}$ del "alboroto", causado por "los que lloraban y plañían" 22; también la eufemística valoración de la "muerte" de "la niña" por Jesús como un "sueño" ${ }^{23}$, así como su "burla" por los presentes ${ }^{24}$; que Él "los expulsó a todos" y, llevando consigo "al padre de la niña y a la madre ${ }^{25}$ y a los (discípulos) que le acompañaban, entró donde" aquélla

16. Eso son el pl. impersonal "érchontai" (Cf. M. Black, o.c., 126-28) y la construcción "apó toû archisynagogos" (Cf. G. Rochais, o.c., 107), así como el aor. "apéthanen"=perfecto arameo (Cf. M. black, o.c., 128-30; G. Rochais, o.c., 107) el verbo "skyllein" (júnico en Mc!) y el subst. "didáskalos"=aram. "rabbí": G. Rochais, o.c., 17.

17. G. Rochais, o.c., 107.

18. "Parakoúsas ton laloúmenon" (Mc 5,37a)=Gén 27,5; Éx 19,9; Núm 7,89 etc. El origen judeo-palestinense de esa expresión se refleja en su uso por el antiguo Targum palestinense al Pentateuco: Cf. TG PI (=Neo Gén 25,5. 6; 37,17; TgPIEx 19,9.

19. Ambos imperativos, únicos en $\mathrm{Mc}$, provienen de su tradiciǒn aramaica: Si el tranquilizante "¡no temas!" (Lc 1,13.30; Act 18,19; 27,24) reproduce la correspondiente fórmula semítica tanto veterotestamentaria (hebr. "al tirá": Cf. S. Plath, Furcht Gottes, Stuttgart 1963, 113-22: 117ss. J. Becker, Gottesfurcht im AT [AB 23], Rom 1965, 50-55; G. Wanke, Phobéo: ThWNT IX 199) como judaica (aram. "lo tidhal": TgPIGén 15,1; 21,17; 26,24; 46,3; TgPIEx 14,13; 20,20 etc.), el imperativo "isólo cree!" es característico del lenguaje (aramaico) de Jesús (cf. infra, n. 33). Es, pues, del todo inexacto afirmar que "el v. 36 está redactado en griego sin huellas de arameísmo": G. Rochais, o.c., 108.

20. Mc 5,37. Las expresiones "no permitió a nadie" y "que le acompañasen", únicas en Mc, pertenecen sin duda a la tradición premarciana, remontándose también a ésta el acompañamiento de los tres mencionados discípulos, testigos asimismo de la transfiguración y plegaria . getsemaníaca del Maestro (Mc 9,2par; 14,33=Mt 26,37): La variabilidad marciana del artículo sólo antes de "Pedro" (Mc 5,37; 14,33; Mt 17,1) o antes de los tres (Mc 9,2) - muestra que esa elección no fue introducida por Mc, sino existía "en la tradición premarciana": Así con R. Pesch, Markus I 307; contra G. Rochais, o.c., 63. 107.

21. El pl. impersonal (="érchontai") seguido de un sing. (="theoréi") es un arameísmo: Cf. M. Black, o.c., 126-28: 127; G. Rochais, o.c., 108.

22. Ninguno de esos vocablos es característico de Mc, quien los recibió de su tradición judeo-cristiana: $\mathrm{Si}$ "thórybos" (alboroto) parece traducir el aram. "hamoná" (M.-J. Lagrange, Marc 143; G. Rochais, o.c., 108), la presencia de "condolientes y plañideras" eran "requisitos necesarios" del judaico rito fúnebre: STR.-Bill., I 521-23: 521.

23. Mc 5,39b. Ese eufemismo, conocido por la literatura veterotestamentaria y judaica (Cf. S. Sabugal, a.c., [supra, n. 21], La fe de Israel... 124, n. 242; La fe del Judaísmo... 153, n. 54) así como por los escritos del NT (1Tes 4,13-15; 5,10; 1Cor 7,39; 11,30; 15,6.18. 20. 51; Act 7,60; Jn 11,11-13; Cf. P. Hoffmann, o.c., [Die Toten], 202-6; M. Völkel, Koimáomai: EWNT II 745s), es único en Mc: Su indiscutible autenticidad jesuana (Cf. infra) muestra que el texto de Mc se enraíza en una tradición aramaica de "la comunidad postpascual", para la que "la muerte es sólo un sueño al que sigue la resurrección": P. Hoffmann, o.c., 203; R. Pesch, Markus I 308. 
estaba (Mc 5,40b) "y tomándole de la mano..." (Mc 5,41a), sintoniza con al tradicional modo reservado de Jesús en la realización de sus prodigios ${ }^{26}$, frecuentemente introducidos y acompañados éstos con un gesto de su mano ${ }^{27}$; a la tradición judeo-cristiana se remonta sin duda el aramaico imperativo anastásico — "italítha, koum!"— de Jesús ${ }^{28}$ así como la inmediata resurrección ("anéste") de la niña ${ }^{29}$, quien "caminaba" ${ }^{30}$, de modo que los cinco testigos del prodigio "quedaron fuera de sí con gran asombro" ${ }^{31}$; tras lo cual Jesús les prohibió "que nadie lo supiese" ${ }^{32}, \mathrm{y}$ "dijo darle de comer" ${ }^{33}$. Éste debió, pues, ser aproximadamente el texto de la fuente o tradición judeo-cristiana, usada por el evangelista Marcos:

"Vino Jairo, uno de los arquisinagogos, y viendo a Jesús cayó a sus pies; y le suplicaba diciendo que su hija estaba al fin de su vida, que viniese y le impusiese las manos, para que se salve y viva. Y (Jesús) se fue con él... Mientras Él hablaba, llegan de la casa del arquisinagogo diciendo: Tu Hija murió, ¿para qué molestar al Maestro? Pero Jesús, oyendo, lo hablado, dijo al arquisinago-

24. "Se burlaban de Él" (Mc 5,40par). La construcción "katangélein"=gen. (única en Mc) es semítica, como lo muestra su infrecuencia en el griego clásico (Cf. H.J. Liddel-G. Scott, Lexicon, ad. voc.) y su frecuencia en los LXX (2Crón 30,10; Tob 2,8 (S); Jdt 12,12; Jb 5,22; 21,3; 30,1; 39,7. 18; 41,21; Sal 24,2; Prov 17,5; 24,52; Ecclo 7,11 (S); 20,17; (Mac 7,34), atestiguada también por Fl. Josefo (Ant. Jud., V 144) y, en su original hebreo, por el Talmud (TjKid 63d): Cf. A. Schaltter, Matthäus 319; K.H. Rengstorf, Geláo: ThWNT I 656-60: 657s.

25. Está última expresión "es aramea y poco griega": G. Rochais, o.c., 108.

26. Cf. Mc 1,44-45par; 5,37-43par; 6,45-46 (=Jn 6,15); 7,37;8,26; Mt 9,30; 12,16; Jn 5,8. 13 etc. Ese "secreto mesiánico" es una definida característica del Jesús histórico: Cf. X. Léon-Dufour, Les Évangiles... 383-85 (trad. españ., 388-40); V. Taylor, Mark² 123s (trad. españ., 138).

27. "Tomando la mano de la niña": Mc 5,41par; Cf. 1,31 (=Mt 8,15). 41par; 8,23. 25.

28. Mc 5,41b. Así lo muestra la (habitual) tradución griega por Mc para su Comunidad helenístico-cristiana, ignara del arameo, pues esa reproducción del original aramaico por el Evangelista "lässt auf eine aramäische Überlieferungsstufe der Erzählung schliessen": R. Pesch, Markus I 309 (lo subrayado es nuestro).

29. Mc 5,42a (=Lc 9,55a): Pertenece a la tradición cristiana el uso del verbo "anístemi"=resurrección temporal de un muerto: Cf. S. Sabugal, a.c., (supra, n. 23), 387, n. 1112 .

30. Mc 5,42a. Esa prueba de la resurrección, frecuente en los neotestamentarios relatos de curaciones (Act 3,8a.b; 14,10; Jn 5,9) pero ausente en los de Mc, no es creación literaria del Evangelista; y su ausencia en el contexto de los relatos anastasiológicos del NT (Lc 7,15; Act 9,$40 ;$ Jn 11,44) muestra que Mc reprodujo una tradición primitiva.

31. Mc 5,42c. Esa frase "contiene un arameísmo notorio" (G. Rochais, o.c., 109; Cf. V. Taylor, Mark 297: trad: españ., 343), prueba de "que Marcos utiliza aquí una fuente palestinense". o una tradición judeo cristiana: $\mathrm{V}$. Taylor, loc. cit.

32. Mc 5,43a. Tras la redacción marciana (Cf. supra, n. 17) late una "tradición" original sobre el imperativo de Jesús al "secreto" (así con V. Taylor, Mark 297: trad. espñ., 344; ya H.B. Swete, Mark 110; M.-J. Lagrange, Marc 145), habitual en la realización de sus milagros (Cf. supra, n. 26); el v. 43a no es, pues, creación literaria de Mc: Contra G. Rochais, o.c., 69-70. 109.

33. Mc 5,43b. Expresión única en Mc y, con toda probabilidad, proviene de su tradición judeo-cristiana, como lo refleja el semitismo "el pendothénai": Cf. V. Taylor, Mark 298 (trad. españ., 344); G. Rochais, o.c., 70. 
go: ¡No temas, sólo cree! Y no dejó que nadie le siguiese, sino a Pedro y Santiago y Juan, hermano de Santiago. Y, llegados a la casa del arquisinagogo, viendo el alboroto y a los que lloraban y plañían, les dijo: ¿Por qué alborotáis y lloráis? ¡La niña no murió, sino duerme! Y se burlaban de Él. Pero Él, echándolos, tomó consigo al padre de la niña y a la madre y a los que le acompañaban; y entrando donde estaba la niña, le tomó la mano y dijo: ¡Talithá, qûm! $\mathrm{E}$ inmediatamente resucitó la niña, y caminaba. $\mathrm{Y}$ todos quedaron fuera de sí, con gran asombro. Jesús les prohibió divulgarlo y dijo: dadle de comer".

Las modificaciones introducidas por la redacción literaria de Mc no alteraron, pues, sustancialmente sus datos tradicionales, cuya interpretación teológica debemos ahora detectar.

b) Digamos de inmediato, que aquélla se refleja ya en la súplica de Jairo a Jesús por su hija, "para que se salve y viva". Al nivel de la tradición evangélica, el verbo "salvar" tuvo muy probablemente un significado religioso; análogo al del interrogante del carcelero filipense a Pablo y Silas sobre lo que debería "hacer para salvarse", o al del logión del Jesús joanneo sobre el envío por el Dios amante de "su Hijo" al mundo "para que se salve" ${ }^{34}$, una "salvación" condicionada en ambos casos a "la fe en el Señor Jesús" o "en el Hijo único" de Dios ${ }^{35}$. El adorante ruego de Jairo por la "salvación de su hija implica, pues, una confesión de fe en Jesús como "el Salvador" ${ }^{36}$ de la que "está en fin de vida" o en una situación existencial humanamente desesperada: ¡Sólo Él puede salvar lo humanamente insalvable! A robustecer aquella fe del padre, menguada por la noticia sobre la muerte de su hija, contribuyó decisivamente la tranquilizante invitación de Jesús — "¡no temas, sólo cree!"- a confiar o apoyarse "sólo" en quien, tras "resucitar de entre los muertos" como "espíritu vivificante" y "como primicias de los que durmieron" o murieron, "destruyó la muerte" e inauguró su señorío sobre toda clase de muertos ${ }^{37}$ : "¡La niña no está muerta, sólo duerme! Un eufemismo que, al nivel de la tradición evangélica, designa el "sueño" de la "muerte" corporal ${ }^{38}$ y espiritual ${ }^{39}$. Tras aquél late, pues, ciertamente, la esperanzadora fe cristiana en el dominio del Señor resucitado sobre la muerte corporal: para Él ésa no es ya eterna e invencible, sino tan pasajera y fácil de superar como un sueño. Así lo mostró con su imperativo anastásico: "¡Talithá, qûm!". Su versión con el verbo "égeire" (Mc y Lc) así como la inmediata resurrección

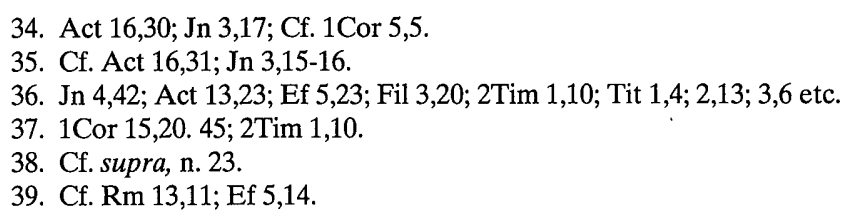


(=anéste") de aquélla (Mc y Lc) son probables indicios de que ese evento anastásico fue interpretado como simbólico adelanto de la ya inaugurada resurrección escatológica de "los muertos" 40: ¡Deben tener "esperanza" los fieles, que se interrogan por la suerte "de los muertos"! El evento anastásico devino pues, al nivel de su tradición evangélica, una catequética exhortación tanto a la fe en el señorío salvador de Jesús sobre la muerte, como a la esperanza en la segura resurrección final de los muertos. No sólo eso. Si en la tradición cristiana el "sueño" designa también la "muerte" espiritual (Cf. supra), el imperativo anastásico de Jesús a la "dormida" o difunta — "ilevántate!" (=égeire") — así como su resurreccional efecto (=anéste") inmediato evocan de modo irresistible a los respectivos de un bautismal himno cristiano antiguo:

"¡Levántate (="égeire"), tủ que duermes, y resucita (="anéste") de entre los muertos, y te iluminará Cristo!" 42 .

El bautizando es, pues, exhortado a "levantarse" o "resucitar" del "sueño" dormido por "los muertos" a causa del pecado ${ }^{43}$, para ser bautismalmente "iluminado" ${ }^{44}$ por "Cristo". Que, al mandato anastásico de Jesús, la "dormida" hija de Jairo se levantó o "resucitó" simboliza probablemente el bautismal paso del "sueño" o muerte espiritual a la participada "resurrección" de Cristo ${ }^{45}$. Tras lo cual, por lo demás, el bautizado debe "caminar en novedad de vida" o "en el Espíritu" del Resucitado y, por cierto, "como hijo de la luz" ${ }^{46}$, existencia post-bautismal simbolizada, sin duda, en el primer gesto de la difunta resucitada: "Y caminaba". ¡Era el inicio del largo y no fácil "camino" cristiano! ${ }^{47}$. Para cuyo fiel recorrido necesita naturalmente aquélla (¡el neófito!) que "se le dé de comer": Que la Iglesia o comunidad adulta en la fe, representada por los cinco cualificados testigos del evento, la alimente - $¡$ ¡dadles vosotros de comer!" ${ }^{48}$ cotidianamente con "el pan nues-

40. ¡Ya "resucitan [=egeírontai] los muertos"! (Mt 11,5=Lc 7,22): Cf. S. Sabugal, La embajada mesiánica de Juan Bautista, Madrid 1980, 135s (=Q). En la tradición cristiana los verbos "anístemi" y "egeírein" designan frecuenemente esa resurrección final: Cf. S. Sabugal, a.c., (supra, n. 23) 388 n. 15; 394, n. 58.

41. Cf. 1 Tes 4,13-18; 1 Cor 15,20-23.

42. Ef 5,14. Para su análisis, Cf. H. Schlier, Der Brief an die Epheser, Düsseldorf 51965, $240-$ 42 (bibliogr.); J. Gnilka, Der Epheserbrief (Herders ThKNT, X. 2), Freiburg 1971, 259-63; H. Halter, Taufe und Ethos (FThSt 106), Freiburg 1977, 277-80; R. Schnackenburg, Der Brief an die Epheser (EKK 10), Neukirchen-Vluyn 1982, 231-34.

43. Cf. Rm 6,23; 7,9-10; Ef 2,5 etc.

44. Cf. Hebr. 6,$4 ; 10,32$.

45. Cf. Rm 6,3-11; Ef 2,4-6; Col 2,12; 3,1-4.

46. Rm 6,5; Gál 5,16; Ef 5,8.

47. Sobre la existencia cristiana como "peregrinación" o "camino" según el NT, Cf. C. Spicq, Vida cristiana y peregrinación, Madrid 1977. 4)s:: S. Sabugal, Credo. La fe de la Iglesia, Zamora 1986, 240-42. 
tro" o el específico alimento cristiano de la Palabra y la Eucaristía ${ }^{49}$. El evento anastásico devino pues también, al nivel de su tradición evangélica, una catequesis bautismal sobre el paso del "sueño" o muerte del pecado a la participada "resurrección" de Cristo, inicio del "camino" cristiano recorrido con el fortificante "alimento" de la Iglesia.

Resumiendo estos análisis: Tras la más antigua redacción literaria de Mc late una tradición judeo-cristiana, sustancialmente idéntica; en cuya fase preredaccional, por lo demás, el evento anástasico de Jesús fue interpretado como una catequesis anastasiológica o exhortación a la fe en el señorío de Jesús sobre la muerte y a la esperanza en la escatológica resurrección de los muertos, así como una catequesis bautismal sobre el paso de la "muerte" a la "resucitada' vida nueva y su inicial "camino" en la Iglesia. Dos catequesis, por lo demás, complementarias. Pues "el camino" iniciado, tras el bautismal paso de la "muerte" a la "vida", sólo puede ser fielmente recorrido por el justo "de fe en fe" animado "por la fe" ${ }^{50}$ sólida en el Señor de la muerte y "la no deludente esperanza" ${ }^{51}$ de la resurrección futura, que precederá al paradisíaco "encuentro con el Señor" para "estar siempre con" Él ${ }^{52}$.

\section{3) El evento histórico}

¿Es la aramaica tradición judeo-cristiana sobre la resurrección de la hija de Jairo por Jesús un producto de la fe pascual de la Comunidad palestinense en el Resucitado o el Señor de la muerte? Así lo han valorado varios autores. Objetivos indicios literarios y temáticos, sin embargo, muestran que aquella tradición primitiva se enraíza en un evento sustancialmente histórico ${ }^{1}$.

a) Así lo muestra ya la prácticamente total ausencia "cristiana" en aquella tradición. Ningún indicio, efectivamente, refleja en ella el influjo postpascual, que los relatos sobre las resurrecciones realizadas por Elías y Eliseo ejercieron ciertamente en algunas anastasiológicas narraciones neotestamentarias $^{2}$. A lo que se suma la falta de datos, que caracterizan la fe pascual. A "Jesús"-así es parcamente llamado- no se le aplica ningún título mesiáni-

48. Mc 6,37par.

49. Ese significado tiene la petición del "pan nuestro cotidiano" (Mt 6,11=Lc 11,3), al nivel de la tradición cristiana: Cf. Sabugal, Abbá. La Oración del Señor, Madrid 1985, 276s.

50. Rm 1,17; Cf. Gál 3,11.

51. $\operatorname{Rm} 5,5$.

52. 1 Tes $4,13-17$.

1. Cf. H. Schürmann, Lukas, I 497; I. H. Marshall, Luke, 341s; J. Gnilka, Markus, I 218s; R. Latourelle, o.c., 150-52.

2. Cf. Lc 7,15 (=1Re 17,23); 8,55a (1Re 17,21s); Act $9,37(=1 \operatorname{Re} 17,19.23 ; 2 \operatorname{Re} 4,10.11) .40 \mathrm{~b}$ $(=2 \operatorname{Re} 4,35 \mathrm{~b}) ; 20,10(=1 \operatorname{Re} 17,21 ; 2 \operatorname{Re} 4,34.35$. Aquellos relatos veterotestamentarios "no reflejan afinidad alguna con" esta tradición evangélica, "de modo que no poseemos indicio indiscutible para una 'transferencia' a Jesús": H. Schürmann, Lukas, I 497. 
co específicamente cristiano ni, como en este contexto hubiera sido normal, se le designa "Señor" ${ }^{3}$ sino sólo "el Maestro" ${ }^{4}$, honorífico título ausente de los neotestamentarios escritos extraevangélicos. Por eso Jairo, sin tributarle la "adoración" cristiana ${ }^{5}$, sencillamaente "cae a sus pies". Se comprende, pues, que en la exhortación de Jesús a creer ("isólo cree!") no se especifique - contra la praxis cristiana- el objeto personal de la fe ${ }^{6}$ ni sus efectos ${ }^{7}$ : ¡Aquel imperativo no tiene analogía en todos los escritos neotestamentarios! No es creación literaria de la tradición postpascual la elección por Jesús de los tres discípulos — "Pedro y Santiago y Juan, hermano de Santiago" " como testigos del prodigio: La tradición cristiana no los menciona siempre por ese orden ni precisa el parentesco de Juan ${ }^{8}$ y sí les designó "columnas" de la Iglesia ${ }^{9}$, epíteto ausente de esta tradición evangélica. El enigmático eufemismo de Jesús - "la niña no murió sino duerme"- no es invención de la tradición cristiana, la cual más bien lo explicó: Así lo refleja el testimonio joanneo sobre el mortal "sueño" del "amigo Lázaro", quien efectivamente "ha muerto" ${ }^{10}$. Tampoco es creación postpascual el gesto anastásico — "tomando la niña de la mano"- de Jesús, como lo muestra su total ausencia en los otros cuatro relatos anastásicos neotestamentarios ${ }^{11}$. $\mathrm{Y}$ ciertamente no es cristiana la desconcertante ausencia total de la conclusiva fe o alabante confesión, normalmente suscitada por el prodigio anastásico ${ }^{12}$. Resultado: Una tradición como ésta, desprovista de vocabulario y temática específicos de la fe cristiana en el resucitado Señor de la muerte, no pudo ser producto de la Comunidad postpascual. ¡Su origen antecede a Pascua!

b) Del todo instructivo, a este respecto, es ya el colorido palestinense de aquella tradición, en sintonía con el escenario geográfico del ministerio de Jesús. Eso refleja, con claridad, el carácter marcadamente semítico y, en particular, aramaico detectado - como hemos visto- en casi todos los datos de

3. Cf. Lc 7,13; Jn 11,27. 32. 34. 39; Act 9,42.

4. Mc 5,35=Lc 8,49. Con el honorífico título "el Maestro" fue designado sin duda el Jesús histórico: Cf. G. Dalman, Die Worte Jesu, Leipzig ${ }^{2} 1930$ (reprod. Darmstadt 1965), 272-80: 276ss; R. H. Fuller, The foundations of New Testament Christology, London 1965, 155s (trad. españ., 163s); F. Fahn, Christologische Hoheitstitel (FRLANT 83), Göttingen ${ }^{31966,76-81 . ~}$

5. Sí en Mt 9,18; Cf. 14,33; 28,9. 17 etc; Lc 24,52 (var.): Supra, n. 44.

6. Cf. Jn 11,27; 20,31; Act 8,37; 9,42; 11,17; 16,31; 1Tes 4,14; Gál 2,16; Rm 3,26; Fil 2,19 etc.

7. Sí en Lc 8,50; Cf. Act 16,31; Rm 3,26. 28; 4,22-24; 5,1; Jn 3,15-18 etc.

8. Cf. Act 1,13; Gál 2,9.

9. Gál 2,9 .

10. Jn 11,11. 14. "La Iglesia primitiva no inventó enigmas de Jesús, sino que por el contrario los explicó ": J. Jeremias, Neutestamentliche Theologie, Gütersloh 1971, 40 (trad. españ., 45). Por lo denás, la ausencia de aquel eufemismo en los relatos sobre las resurrecciones realizadas por Pedro (Act 9,36-43) y Pablo (Act 20,7-12) muestra cuán ajeno era a la tradición cristiana y qué desacertado es atribuirlo a "una inserción... catequética" de la comunidad; Contra G. Rochais, o.c., 109.

11. Cf. Lc 7,14; Jn 11,43; Act 9,40; 20,10.

12. Cf. Act 9,42; Jn 11,45; Lc 7,16. 
la tradición evangélica (Cf. supra). Por lo demás, judeo-palestinense es el mismo nombre de "Jairo" ${ }^{13} \mathrm{y}$, por tanto, su profesión religiosa como "uno de los arquisinagogos" o directores del culto sinagogal ${ }^{14}$. Palestinense -al menos en ciertos ambientes - era también la curativa "imposición de las manos", ciertamente practicada por Jesús y -en ocasiones - a ruego de otro ${ }^{15}$, así como la necesaria presencia -en la cámara mortuoria- de "condolientes y plañideras" ${ }^{16}$. Y si la eufemística valoración de la "muerte" como un "sueño" era usual en el palestinense judaísmo apócrifo y rabbínico ${ }^{17}$, el imperativo anastásico de Jesús — " ¡talithá koúm!"— reproduce con fidelidad el dialecto galilaico del arameo palestinense ${ }^{18}$. Jesús pudo pues ser rogado por "Jairo, uno de los arquisinagos" a "imponer las manos" sobre su "hija" gravemente enferma o "al fin" de vida y, tras morir ésta, valorar su muerte como un sueño ante quienes "lloraban y plañían", para resucitarla seguidamente con la orden: ¡Talithá koûm!. ¿Lo hizo realmente? Varios indicios parecen imponer una respuesta afirmativa.

c) Los datos sustanciales de la tradición evangélica sintonizan ciertamente con el modo de obrar y hablar de Jesús histórico. No fue la única vez que, rogado el Maestro por otro a "imponer las manos" sobre un enfermo, accedió a esa súplica y, sin practicar aquel gesto, curó diversamente al paciente ${ }^{19}$ : Que accediese al análogo ruego de Jairo ${ }^{20} \mathrm{y}$, con un gesto diverso, resucitase a la muerta ${ }^{21}$ sintoniza, pues, con su modo de obrar. Con éste se armoniza también la elección de "Pedro, Santiago y Juan" para presenciar el prodigio, elegidos asimismo por Jesús como testigos de otros dos culminantes eventos - su transfiguración y crisis getsemaníaca- de su ministerio ${ }^{22}$ : $\mathrm{Si}$

13. Cf. supra, n. 6.

14. A este respecto, Cf. E. Schürer, Geschichte des jüdichen Volkes, II, Leipzig 1907, 509 12: 511s; Id., Historia del pueblo judio (ed. G. Vermés-F. Miller-M. Black), II, Madrid 1985, 562 65: 564s (bibliogr.); STR.-Bill., IV 145-47; W. Schrage, Archisynágogos: ThWNT VII 842-45: 843s. Que "Jairo" era "uno de los arquisinagogos" significa que pertenecía a esa clase o categoría sinagogal: Cf. E. Schürer, Geschichte, 512; Historia, 565; STR.-BILL., IV 146g (fuentes judaicas).

15. Cf. supra, n. 13.

16. Cf. supra, n. 22.

17. Cf. supra, n. 52; STR.-BILL., I 523; P. Hoffmann, o..., 197-201.

18. Si "talithá" es la reproducción exacta del femenino aram. "telîthá" (=muchacha, joven), "koúm" transcribe también el respectivo imperativo aram. "qûm". Que en vez del fem. "koumi" (ADO pm it vg sy ${ }^{\mathrm{pe}}$ ), correspondiente al sustantivo fem. " "talithá", se use el mas. "koum" (aram. "qûm"), se debe a que en arameo galilaico se usaba el masc. por el femenino: Cf. G. Dalman, Grammatik des jüdisch-palästinischen Aramäische, Leipzig ${ }^{21927, ~ 275 ; ~ J . ~ J e r e m i a s, ~ o . c ., ~ 16, ~}$ n. 13 (trad. españ., 17, n. 13).

19. Cf. Mc 7,32ss.

20. Mc 5,23-24par.

21. Mc 5,41par.

22. Mc 9,2par; 14,33=Mt 26,37. 
aquella elección implica la valoración de este prodigio anastásico por Jesús como uno de sus culminantes signos mesiánicos, su motivación responde probablemente a que los tres elegidos testifiquen su señorío sobre la muerte ante los otros nueve discípulos, así también ellos educados gradualmente por el Maestro a "creer sin ver" ${ }^{23}$. A "sólo" creer o apoyarse en su poder sobre la muerte exhortó, de modo categórico, el doble imperativo de Jesús — " ¡no temas, sólo cree! - al arquisinagogo: Un modo de hablar sinfónico, por cierto, con una de las caractarísticas del "lenguaje de Cristo" o de quien, usando con frecuencia el imperativo, habló "exigiendo categóricamente" y "exhortando urgentemente" ${ }^{24}$, sintonizando asimismo aquella exhortación a Jairo — "jsólo cree!" - con la habitual exigencia previa de la fe por Jesús, en la realización de sus milagros ${ }^{25}$. Por lo demás, el enigmático eufemismo del Maestro sobre el "sueño" mortal de la difunta hija de Jairo sólo puede ser calificado de "frase sibilina" y atribuido a una postpascual "inserción... catequética" por quien ${ }^{26}$ ignore $\mathrm{u}$ olvide que precisamente "los enigmas" o el uso de palabras enigmáticas son una de las "caraterísticas de la mismísima voz" de Jesús ${ }^{27}$, quien, asimismo, acostumbró preceder o acompañar sus signos mesiánicos (=milagros) con un judaicamente "escandalizante" dicho o gesto ${ }^{28}$, que tanto al interesado como a los circunstantes les ponía en la libre alternativa de creer o no en Él, suscitando efectivamente con ello la reacción creyente o incrédula de aquéllos ${ }^{29}$; análoga finalidad tuvo, muy probablemente, aquel enigmático eufemismo de Jesús: Suscitar en los circunstantes condolientes una libre reacción creyente o incrédula respecto a Él, "de quien" aquéllos en efecto incrédulamente "se burlaban". Añadamos seguidamente, que aquel eufemismo implica ciertamente una valoración de la muerte "como la ve Dios", para quien "la muerte ya no es muerte" eterna e invencible sino sólo pasajera y superable como un sueño ${ }^{30}$, reflejando por

23. Cf. Jn 4,48; Mc 8,11-13par.

24. H. Schürmann, Die Sprache des Christus: BZ 2 (1958) 54-84: 80-82.

25. Cf. Mc 5,36 (=Lc 8,50); 9,23; Mt 9,28; Jn 4,47s; 11,23-27. 40 etc. Jesús rehúsa realizar el milagro, cuando no encuentra fe: Cf. Mc 5,5-6a (Mt 13,58); Mt 12,28-32=Lc 11,29.

26. G. Rochais, o.c., 108s.

27. J. Jeremias, o.c., 39s (trad. españ., 45s).

28. Perdona "los pecados" (Mc 2,1-12: v. 5par), "toca" a los leprosos (Mc 1,41par) o a los miembros "impuros" de los enfermos (Mc 1,44par; 7,33; Mt 9,29; 20,34; Cf. Mc 8,23. 25) y cura "en sábado": Mc 3,1-6par; Lc 13,10-13; Jn 5,1-16; 9,1-7. 14.

29. Cf. Mc 1,44par; 2,6-7. 12par; 3,6par; 7,36s; Lc 13,14; Jn 5,10. 16; 9,16-17. 24. 33. 35-37.

30. V. Taylor, Mark 295 (trad. espñ., 341); E. Lohmeyer, Markus 106; H. Schürmann, Lukas, I 495.

31. R. Pesch, Mark, I 308.

32. E. Fuchs, Zur Frage nach dem historischen Jesus: ZThK 53 (1956) 210-29: 219; Cf. también: E. Käsemann, Das problem des historischen Jesus: ZThK 51 (1954) 125-53: 144s M. Smith, 
ello "la pretensión inaudita... del mismo Dios" 31: Una valoración.y pretensión en total sintonía con la habitual praxis de quien -Jesús- obró y exigió y habló "como si estuviera en lugar de Dios" ${ }^{32}$. Asi realizó Él este signo anastásico. Pues si su grito imperativo - ¡talithá koûm! - nos ha conservado dos de los mismísimos vocablos arameo-galilaicos propios de la lengua materna de Jesús ${ }^{33}$, reflejando asimismo el carácter imperioso y exigente de su lenguaje ${ }^{34}$, aquel anastásico imperativo fue pronunciado por quien, sin previa oración a Dios o invocación de su poder ${ }^{35}$ se arrogó la potestad divina de resucitar a esa muerta y, con ello, se atribuyó el mismo poder anastásico reservado por el judaísmo exclusivamente a Dios ${ }^{36}$. ¡Así habló y obró Jesús! En perfecta sintonía, por lo demás, con "la soberanía" de su hablar y actuar así como con el "poder extraordinario" desplegado en sus milagros ${ }^{37}$ : Consciente de "haberle sido entregado" por "el Padre todo" poder y revelación ${ }^{38}$, quien ejerció la potestad divina de "perdonar los pecados" ${ }^{39}$ se atribuyó también el poder divino de resucitar a "los muertos ${ }^{40}$, manifestando así a los hombres su señorío o dominio sobre lo que —el pecado y el temor a la muerteradicalmente envilece y esclaviza y mata. Por lo demás, si la "prohibición a divulgar" el evento anastásico se ajusta perfectamente al "secreto mesiánico" reiteradamente impuesto por Jesús tras sus milagros, sólo comprensibles como signos salvadores tras su resurrección o la plena revelación de su digni-

Tannaic paralleles to the Gospels, Philadelphia 1968, 153-54. 159; M. Hengel, Nachfolge und Charisma (BZNW 34), Berlín 1968, 70-81. 98; J. Jeremias, o.c., 198-201. 239-43 (trad. españ., 240-44. 291-96); Ch. H. Dodd, El Fundador del Cristianismo, Barcelona 1975, 65s; S. Sabugal, La embajada, 154; Abbá, 420. 639-42.

33. Cf. J. Jeremias, o.c., 14-19: 17 (trad. españ., 15-21: 18); supra, 'n. 18. Sobre el arameo galilaico, como lengua materna de Jesús, Cf. S. Sabugal, Abbá, 217-23: 321ss (bibliogr.).

34. Cf. supra, n. 24.

35. Como lo hicieron los dos taumaturgos veterotestamentarios (Cf. 1Re 17,20-21; $2 \mathrm{Re}$ 4,33) y luego Pedro: Cf. Act $9,40$.

36. Cf. supra, n. 21. La explicación del relato como desvelamiento de una muerte aparente (E. Hirsch, Frühgeschichte des Evangeliums, I, Tübingen ${ }^{21951,42 s ; ~ V . ~ T a y l o r, ~ M a r k ~ 295: ~ t r a d . ~}$ españ., 342; E. Haenchen, Der Weg Jesu, Berlin $\left.{ }^{2} 1968,210\right)$ o como curación de la gravemente enferma por Jesús, interpretada luego como un evento anastásico por la tradición pre-marciana (R. Pesch, Markus, I 312-14; G. Rochais, o.c., 108-11) no responde a un científico análisis histórico-tradicional del relato evangélico, el cual ha mostrado que se trató "d'incidents réels" (A. Loisy, o.c., 826; M.-J. Lagrange, Marc 145s) o "de una muerte real" y de "una victoria real de Jesús sobre la muerte": R. Latourelle, o.c., 151.

37. X. Léon-Dufour, Les Évangiles et l'histoire de Jésus, Paris 1963, 373 (trad. españ., 333);

E. Trocmé, Jesús de Nazaret (trad. españ.), Barcelona 1974, 146.

38. Mt 11,27a (=Lc 10,22a): Cf. S. Sabugal, Abbá 391.

39. Mc 2,5. 10-11par: Cf. S. Sabugal, Abbá 641s; Pecado y reconciliación en el mensaje de Jesús, Palermo 1985, 102-4

40. Mt 11,5 (=Lc 7,22): Cf. S. Sabugal, La embajada, 185-88; Id., a.c., (supra, n. 31=Lc 7,11-

17) 480; Id., La resurrección de Lázaro (Jn 11,1-54): EstAg 24 (1989) 55-70: 70.

41. Cf. S. Sabugal, Christós, 130s. 
dad mesiánica correpondiente al preanunciado "Siervo de Dios" paciente y glorificado ${ }^{41}$, su orden de "alimentar" a la resucitada pone de relieve "la bondad" o "solícita compasión" de Jesús ${ }^{42}$, sintonizando desde luego con aquel "su carácter misericordioso" frecuentemente reflejado en los evangéli$\cos$ relatos semeiológicos ${ }^{43}$.

Sintetizando estos desarrollos, podemos decir que la tradición judeo-cristiana sobre la resurrrección de la hija de Jairo por Jesús se enraíza en el sólido subsuelo de un evento histórico: El Maestro accedió al inicial ruego humilde del arquisinagogo por su hija "al fin" de la vida o gravemente enferme y, tras la defunción de ésta, superó la menguada fe de aquél con la exhortación a creer o apoyarse "sólo" en su poder, para el que vencer la muerte no es más difícil que despertar de un sueño; eso debían atestiguar sus tres discípulos así como los padres de la difunta, elegidos por Jesús como cualificados testigos de uno de sus culminantes signos mesiánicos o de su primer signo anastásico; por Él realizado con un gesto sencillo y un imperioso mandato, que desveló su sobrehumana potesad sobre la muerte y su señorío divino sobre los muertos. El siempre actual mensaje salvador de aquel signo anastásico es evidente; si quien se encuentre "al fin" de vida o en humanamente desesperada situación existencial sabe que Jesús no es sordo y sí escucha con prontitud a todo el que solicite humildemente su auxilio salvador, la potestad divina desplegada por el Maestro en la difunta hija de Jairo alienta la esperanza de quien se sienta oprimido por eventos de muerte y, con fe en el Señor de los muertos, invoque sobre aquéllos su liberador poder anastásico. ¡También ese creyente hoy, como la hija de Jairo ayer, experimentará que la muerte - toda realidad de muerte — no tiene ya la última palabra y sí está sometida a la palabra salvadora del Resucitado y Resucitador!

Santos SABUGAL, O.S.A.

Instituto Patrístico "Augustinianum"

Roma 344).

42. H.B. Swete, Mark 110; M.-J. Lagrange, Marc 145; V. Taylor, Mark 298 (trad. españ.,

43. E. Trocmé, o.c., 135-50: 148. 